\title{
Birnessite nanorod-mediated decomposition of methylene blue with common oxidants
}

\author{
R. Kannan · K. Govindan · S. Selvaraj • \\ P. Ravichandiran $\cdot$ S. Vasanthkumar
}

Received: 21 February 2012/ Accepted: 26 August 2012/Published online: 20 October 2012

(C) The Author(s) 2012. This article is published with open access at Springerlink.com

\begin{abstract}
In this paper, the birnessite nanorods (BN) were synthesized by microwave-assisted hydrothermal method and was characterized by powder X-ray diffraction measurements (XRD), scanning electron microscopy (SEM) with energy dispersive X-ray spectroscopy (EDX), and surface area (BET) analyzer. These results confirm the formation of birnessite nanorods. The catalytic decomposition profile of methylene blue by birnessite nanorods was tested. The effect of oxidants peroxomonosulfate (PMS) and peroxodisulfate (PDS) was compared with hydrogen peroxide $\left(\mathrm{H}_{2} \mathrm{O}_{2}\right)$. Among these oxidants, PDS exhibits a high degree of decomposition of more than $80 \%$ mineralization, achieved in $4 \mathrm{~h}$ when compared to PMS and $\mathrm{H}_{2} \mathrm{O}_{2}$. The decomposition was examined using varying amount of catalyst, which showed the dye decomposition activity to be proportional to the amount of the catalyst. The powder XRD studies showed no changes in the structure of birnessite nanorods, implying that these reactions are surface controlled.
\end{abstract}

\section{R. Kannan}

Department of Chemistry, Sona College of Technology, Salem 636005 , India

R. Kannan · S. Vasanthkumar $(\bowtie)$

School of Nanosciences and Technology, Karunya University, Coimbatore 641 114, India

e-mail: kumar2359@yahoo.com

\section{K. Govindan}

Water Chemistry Lab, Karunya University, Coimbatore 641 114, India

S. Selvaraj · P. Ravichandiran · S. Vasanthkumar Department of Chemistry, School of Science and Humanities, Karunya University, Coimbatore 641 114, India
Keywords Birnessite $\cdot$ Manganese oxide $\cdot$ Methylene blue $\cdot$ Hydrogen peroxide Peroxomonosulfate . Peroxodisulfate

\section{Introduction}

Decolorization of synthetic dyes attracted considerable attention in the past two decades. Dyeing and finishing operations produce large quantities of wastewater that contains number of organic dyestuff, which are toxic and potential carcinogenic nature (Reisch 1988). There exist a number of methods for treating these effluents, such as coagulation, adsorption on activated carbon, chemical oxidation (advanced oxidation process-AOPs), and biological treatment (Andreozzy et al. 1999; Parag and Aniruddha 2004; Watts and Teel 2006; Furman et al. 2009, 2010; Kitajima et al. 1978; Zhou et al. 1998). Among them, AOPs have already been used for the treatment of wastewater.

In situ chemical oxidation (ISCO), the category of AOPs has been identified as offering techniques with potential application for the removal of color. The most common ISCO processes are catalyzed $\mathrm{H}_{2} \mathrm{O}_{2}$ propagations (CHP), permanganate, and activated persulfate (Watts and Teel 2006). Many of these processes operate through the generation of free radicals such as $-\mathrm{OH}$ and superoxide. Sulfate radical $\left(\mathrm{SO}_{3}{ }^{-2-}\right)$-based AOPs, in which PMS or PDS is used as a strong oxidant that can attack most of the organic compounds present in wastewater (Furman et al. 2009, 2010; Kitajima et al. 1978; Zhou et al. 1998; Watts and Teel 2006). Activation of these oxidants is done by a number of ways (Brock et al. 1988; Suib 2008; Anipsitakis and Dionysiou 2004). Among them metal- and metal oxide-mediated decomposition of dye has been explained 
(Anipsitakis and Dionysiou 2004; Segal et al. 1997). Recently, the decomposition efficiency of these peroxides has been studied, it reveals that $\mathrm{Co}(\mathrm{II})$ and $\mathrm{Ru}(\mathrm{III})$ were best in catalyst for PMS activation, $\mathrm{Fe}$ (II/III) and $\mathrm{Ag}(\mathrm{I})$ were best activators for $\mathrm{H}_{2} \mathrm{O}_{2}$ and PDS, respectively (Anipsitakis and Dionysiou 2004). Persulfate is usually activated to increase its reactivity; laboratory activators include UV light and heat, but the most common activators used for ISCO applications are chelated iron and base (Furman et al. 2009; Kitajima et al. 1978; Zhou et al. 1998; Watts and Teel 2006). The primary limitation of activated persulfate is the minimal knowledge of its reaction pathways in the subsurface.

Manganese oxide with different structures have been widely studied due to their diverse physical and chemical properties, and they find extensive application in the field of catalysis, and batteries (Zhou et al. 1998; Brock et al. 1988; Suib 2008; Anipsitakis and Dionysiou 2004; Segal et al. 1997) etc. Manganese oxide-mediated CHP is a field of great interest due to the high surface area and high stability (Furman et al. 2009; Kitajima et al. 1978; Zhou et al. 1998; Watts and Teel 2006; Segal et al. 1997). The objective of the present communication is to study the effect of birnessite nanorods for the decomposition of organic dye (methylene blue) in the presence of common oxidants such as $\mathrm{H}_{2} \mathrm{O}_{2}$, PMS and PDS. The experimental results showed that PMS shows higher degree of decomposition rate compared to $\mathrm{PDS}$ and $\mathrm{H}_{2} \mathrm{O}_{2}$.

\section{Experimental}

Manganese chloride, sodium hydroxide, hydrogen peroxide (30 \% v/v, S. D. Fine Chemicals, India), methylene blue (Qualigence, India), hydrogen peroxide, potassium peroxomono sulfate and peroxodisulfide (Merck, India), and all the other reagents were of the highest purity and used as received.

The birnessite nanorods $(\mathrm{BN})$ were prepared by a hydrothermal method. In brief, a cold $\left(-2{ }^{\circ} \mathrm{C}\right)$ solution of sodium hydroxide $(5 \mathrm{M}, 100 \mathrm{ml})$ and $\mathrm{H}_{2} \mathrm{O}_{2}(2 \mathrm{ml})$ mixture was added drop wise into an aqueous solution of $\mathrm{MnCl}_{2}$ $(0.5 \mathrm{M}, 100 \mathrm{ml})$, and the whole reaction was carried out in an ultrasonic bath (PCI, India, $35 \mathrm{kHz}$ ), under a current of air using a commercial aeration motor. After $3 \mathrm{~h}$, the precipitate formed was removed by centrifugation. It was washed several times with double distilled water and dried in a domestic microwave oven. The prepared material was characterized by FTIR (Shimadzu spectrum I), Powder XRD (X-6000, Shimadzu), SEM (JSM 6390, JEOL) and HRTEM (JEOL 2100). The structural details of the catalytic material before and after the reaction were studied.
The catalytic activity (decomposition) was conducted with constant stirring (500 RPM) under ambient atmospheric conditions in a $250 \mathrm{~mL}$ amber glass bottle in order to prevent absorption of light which contains $100 \mathrm{ml}$ of dye solution and the catalyst. Samples for analysis were withdrawn $(1-2 \mathrm{ml})$ at regular intervals of time and tested. The catalyst was separated from the solution by filtration using a $0.22 \mu \mathrm{m}$ PVDF filter followed by centrifugation at 8,000 RPM. The decrease in the concentration of the dye was determined spectrophotometrically using a UV-vis spectrophotometer (JASCO V-670) by the absorbance of the methylene blue at its $\lambda_{\max }(664 \mathrm{~nm})$.

\section{Results and discussion}

\section{Physical characterization of the BN material}

The FTIR spectra recorded for the BN material show significant IR signals at 3,384 and at $1,597 \mathrm{~cm}^{-1}$ corresponding to the $\mathrm{O}-\mathrm{H}_{\text {str }}$, and $\mathrm{O}-\mathrm{H}_{\text {bending }}$ frequencies, respectively. These signals indicate the presence of water molecules in the BN material. The bands at 515 and $480 \mathrm{~cm}^{-1}$ correspond to the $\mathrm{Mn}-\mathrm{O}$ bond. The sharp peak at $780 \mathrm{~cm}^{-1}$ confirms the presence of tunnel structure (Kang et al. 2007). The powder XRD measurements were preformed to determine the structure of the $\mathrm{BN}$ material. Figure 1a shows, sharp peaks of $2 \theta$ at 12, 18 indicative of the formation of birnesite, a layered type of manganese oxide with the interlayer spacing of $6.9 \AA(2 \theta=12.7)$. A few less dominant peaks are also observed which indicate the formation of $\mathrm{MnO}_{2}$, and $\mathrm{Mn}_{3} \mathrm{O}_{4}$ phases. This is due to the quick hydrothermal process by the microwave irradiation. These mixed valence manganese oxide material are bound to act as a good catalyst for a number of organic oxidation reaction (Brock et al. 1988; Suib 2008; Anipsitakis and Dionysiou 2004). Therefore, the BN material was employed for the decomposition of methylene blue dye.

Powder XRD measurements were made on $\mathrm{BN}$ before and after the reaction to check for any changes in the structure. The reaction was scaled up to get sufficient amount of catalyst for the analysis. About $500 \mathrm{mg}$ of catalyst in $5 \times 10^{-5} \mathrm{mg} / \mathrm{L}$ of dye with $0.05 \mathrm{mM}$ of $\mathrm{H}_{2} \mathrm{O}_{2}$, PDS and PMS was used to carry out reaction. The catalyst was recovered and dried in a hot air oven at $60{ }^{\circ} \mathrm{C}$ for $12 \mathrm{~h}$ and analyzed. The UV-Vis data showed a similar behavior as before. The powder XRD pattern of the catalyst [BN] before and the after the reaction is shown in Fig 1a. The XRD patterns of the catalyst before and after the reaction are similar to the earlier patterns which were observed. With the addition of the oxidants, the interlayer distance $2 \theta$ at 12 gets increased and all other peaks are same as before, a fact which clearly shows that the catalyst is still effective 


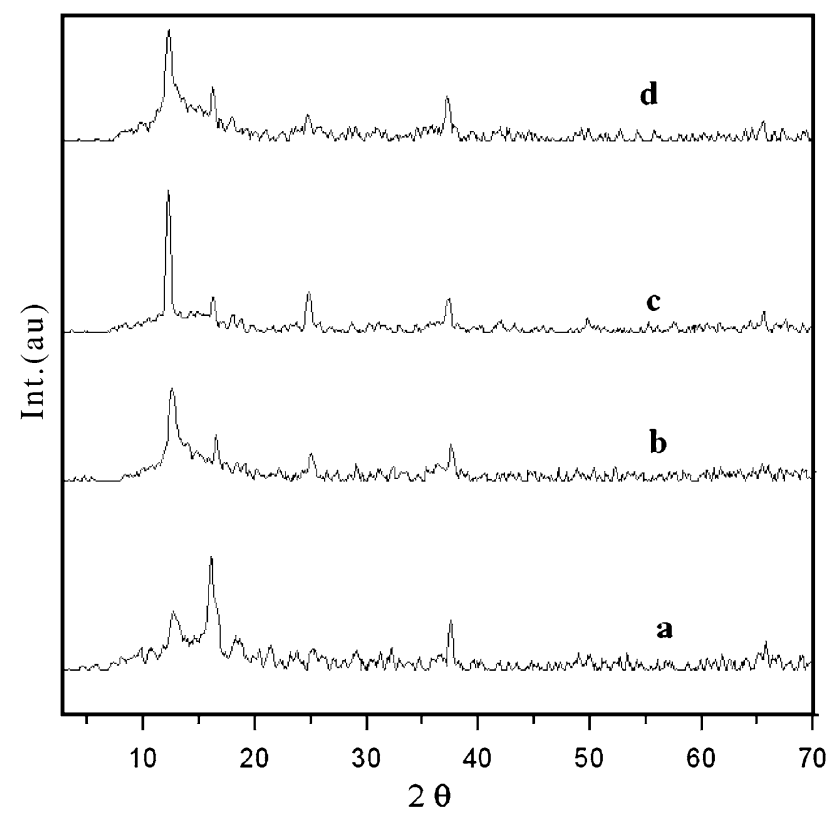

Fig. 1 Powder XRD patterns of Birnessite Nanorod material $a$ before reaction, after reaction with $b \mathrm{H}_{2} \mathrm{O}_{2}, c$ PDS and $d$ PMS

and does not get affected by the oxidants. However, slightly higher $d$ spacing values are observed after the reaction. For example, comparison of the $\mathrm{X}$-ray patterns in Fig. 1a to those of Fig. 1b-d shows that the peak at $12 \AA$ with $d$ spacing $6.9 \AA-7.18\left(\mathrm{H}_{2} \mathrm{O}_{2}\right), 7.23$ (PMS) and 7.17 (PDS). This is due to the penetration of water/hydrated molecules into the interlayers of sheets.

The structural morphology of the BN was examined by SEM and TEM analysis. Figure 2a exposed the presence of several bundles of nanorods. A careful analysis of Fig. 2b, c indicates that the $\mathrm{BN}$ has grown uniformly as nanorods with needle-like nanoclusters. This is due to the cavitations effect of ultrasonic irradiation. The particle size distribution results also suggest that the material is uniformly distributed and the mean particle size is $32.5 \mathrm{~nm}$ (Fig. 2d). The surface area measurement of the prepared BN shows it to be about $61 \mathrm{~m}^{2} / \mathrm{g}$, and the conventional heating process gives the surface area to be around $23 \mathrm{~m}^{2} / \mathrm{g}$. This difference is due to the quick heating process taking place in the microwave.

Catalytic decomposition of methylene blue with BN and common oxidants

At the surface of $\mathrm{BN}$, there is the generation of active radical (both sulfate and hydroxyl). The $\mathrm{BN}$ comprises mixed valence manganese oxide materials. The common oxidation state is between 2 and 3. The generation of radicals would be explained by taking $\mathrm{Mn}^{2+}$ ion. Initially, the oxidants react with $\mathrm{BN}$ surface and produce the radical and the oxidized surface of $\mathrm{BN}$ is stabilized by regaining of excess electron released during the degradation of the pollutant/compound. This is explained by a schematic diagram (Fig. 3). The following reaction shows how the radical is being generated by the oxidants.

The effect of the catalyst (BN) required for the decomposition of MB was studied at a fixed amount of $[\mathrm{MB}]=250 \mathrm{ml}\left(10^{-5} \mathrm{M}\right)$ in aqueous solution (Fig. 4a). The amount of BN was varied between 20 and $120 \mathrm{mg} / \mathrm{L}$, in order to optimize the amount of catalyst for the effective catalytic decomposition of MB. The straight line relationship was obtained between $2+\log (\mathrm{OD})$ versus reaction time. Figure $4 \mathrm{~b}$ shows that, as the amount of catalyst increases, the decolourization rate also steadily increases. This is due to the adsorption of dye on the catalyst. The maximum efficiency was achieved at a concentration of $100 \mathrm{mg} / \mathrm{L}$. At this concentration, the active surface areas are occupied by the dye molecules. The rest of the experiments was carried out using the optimum concentration of the catalyst, which is $100 \mathrm{mg} / \mathrm{L}$.

The BN catalyzed decomposition of dye with oxidant such as PMS was studied by varying $[\mathrm{PMS}]=0.01-0.05$ $\mathrm{mM}$ at constant $[\mathrm{MB}]=250 \mathrm{ml}\left(10^{-5} \mathrm{M}\right)$ and $\left[\mathrm{MnO}_{2}\right]=$ $100 \mathrm{mg} / \mathrm{L}$. There is a logarithmic change in dye concentration with reaction time. The obtained $k^{\prime}$ values are shown in Fig. 4c. It can be seen that a steady rise in the decolourization rate was observed with the entire range of [PMS] (Fig. 4d). This may be due to the generation of sulphate radical (reactions 1 and 2).

$\mathrm{Mn}^{n+}+\mathrm{HSO}_{5}^{-} \rightarrow \mathrm{Mn}^{(n+1)+}+\mathrm{OH}^{-}+\mathrm{SO}_{4}^{-}$
$\mathrm{Mn}^{\mathrm{n}+}+\mathrm{HSO}_{5}^{-} \rightarrow\left[\mathrm{Mn}^{(\mathrm{n}+1)}+\mathrm{SO}_{4}^{2-}\right]+\mathrm{OH}^{-}$

In order to understand the effect of concentration of PDS on the catalytic decomposition of MB, the concentration of PDS was varied from 0.01 to $0.05 \mathrm{mM}$, keeping constantly the concentration of $[\mathrm{MB}]$ at $10^{-5} \mathrm{M}$ and the amount of $[\mathrm{BN}]$ as $100 \mathrm{mg} / \mathrm{L}$. The plot of natural logarithm of change in concentration of the dye versus reaction time shows a good linear approximation over the entire range of PDS (Fig. 4e) and the rate constants were found to increase with increase in the concentration of PDS as shown in Fig. 4f. The increase in decomposition rate constant of dye in the presence of PDS is due to the direct involvement of sulphate radicals. In this reaction, mixed valence manganese ion present in the $\mathrm{BN}$ acts as intermediated electron transfer catalyst to improve the decomposition of dye. The role of catalyst is still unclear.

$\mathrm{S}_{2} \mathrm{O}_{8} \rightarrow 2 \mathrm{SO}_{4}{ }^{-}$

Considerable attention has been paid as the hydrogen peroxide as oxidant in various industrial applications (Watts and Teel 2006) [16]. Several species including 
Fig. 2 a Scanning electron microscopic image. b, c Transmission electron microscopic images and d particle-size distribution of birnessite nanorods
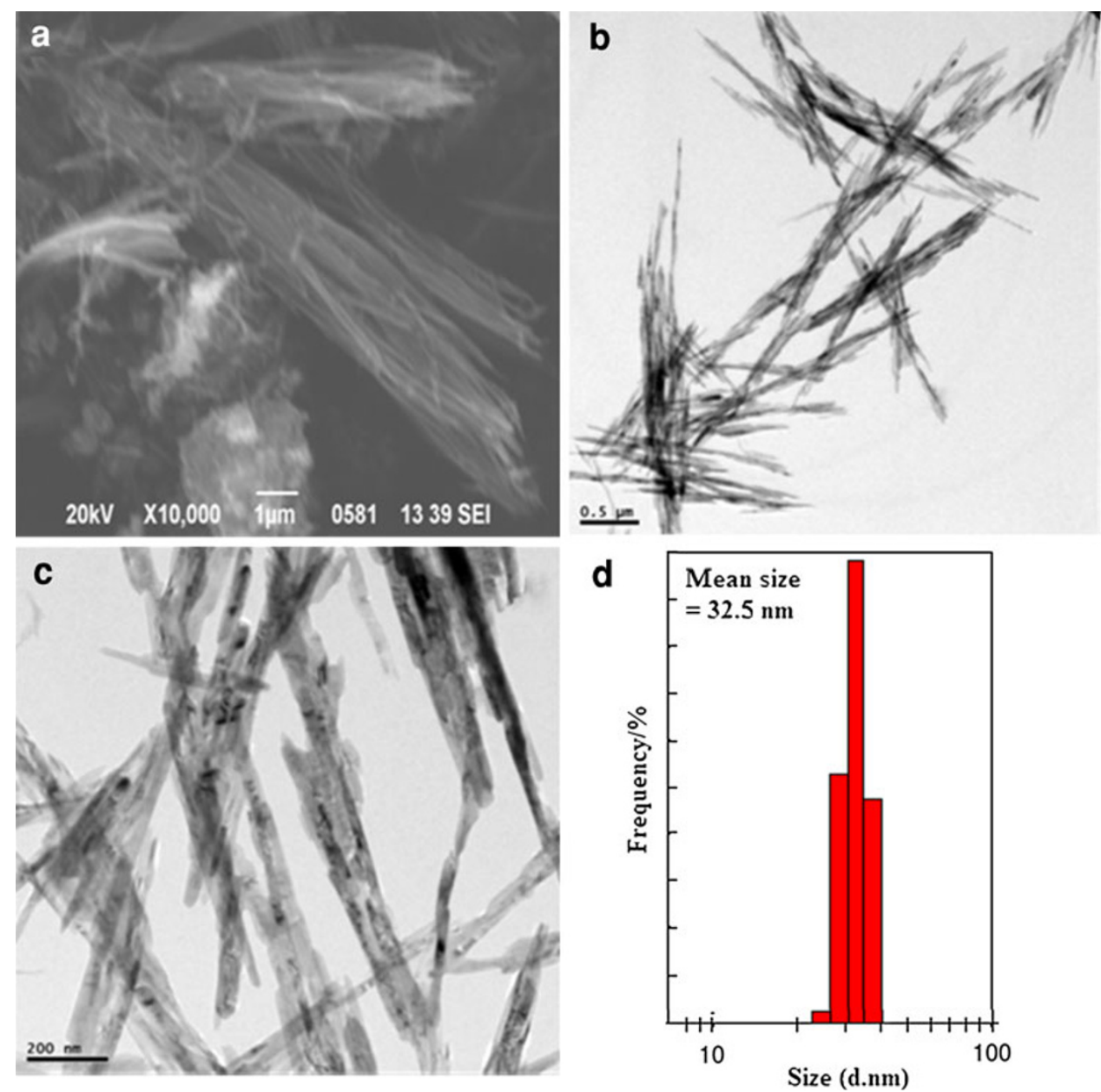

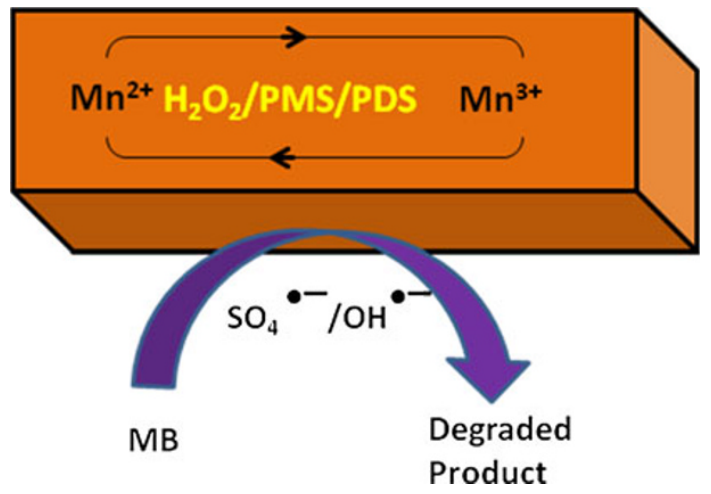

Fig. 3 Schematic representation of oxidative degradation of methylene blue dye on the birnessite nano rods

$\cdot \mathrm{OH}, \cdot \mathrm{OOH}$ or ${ }^{-\cdot} \mathrm{O}_{2}$ are involved in the decomposition reaction (Watts and Teel 2006), however the mechanism is still unclear. It is widely known that hydrogen peroxide is not active at atmospheric temperature. Therefore, a number of methods have been reported, to activate the $\mathrm{H}_{2} \mathrm{O}_{2}$, including high temperature, metal activation, higher $\mathrm{pH}$ etc., (Furman et al. 2009; Brock et al. 1988) Among them, metal-activated peroxide exhibits better results for method destruction of organic molecules (Brock et al. 1988). Figure $4 \mathrm{~g}, \mathrm{~h}$ indicates the effect of concentration of hydrogen peroxide on the catalytic decolourization of $\mathrm{MB}$. These experiments were carried out by varying the concentration of $\mathrm{H}_{2} \mathrm{O}_{2}$ from 0.01 to $0.05 \mathrm{mM}$, while constantly maintaining the $[\mathrm{MB}]$ at $10^{-5} \mathrm{M}$ and the catalyst i.e., $[\mathrm{BN}]$ at $100 \mathrm{mg} / \mathrm{L}$. The results show the decomposition to increase with increase in concentration of $\mathrm{H}_{2} \mathrm{O}_{2}$. In general, $\mathrm{MnO}_{2}$-mediated catalyst decomposes the hydrogen peroxide to produce superoxide radical $\left({ }^{-} \mathrm{O}_{2}\right)$ and this superoxide species subsequently degrades the dye molecules (Eqs. 4-6) (Furman et al. 2009; Kitajima et al. 1978; Watts and Teel 2006; Segal et al. 1997). Thus, BN will act as an excellent intermediate electron transfer mediator to degrade the organic molecule (dye).

$$
\begin{aligned}
& \mathrm{H}_{2} \mathrm{O}_{2} \rightarrow 2 \cdot \mathrm{OH} \\
& \mathrm{Mn}^{2+}(\text { surface })+\mathrm{H}_{2} \mathrm{O}_{2} \rightarrow \mathrm{Mn}^{3+}(\text { surface })+\mathrm{HO}+\mathrm{OH}^{-} \\
& \mathrm{RH}+\mathrm{HO} \cdot \rightarrow \mathrm{R} \cdot+\mathrm{H}_{2} \mathrm{O}
\end{aligned}
$$


(a)

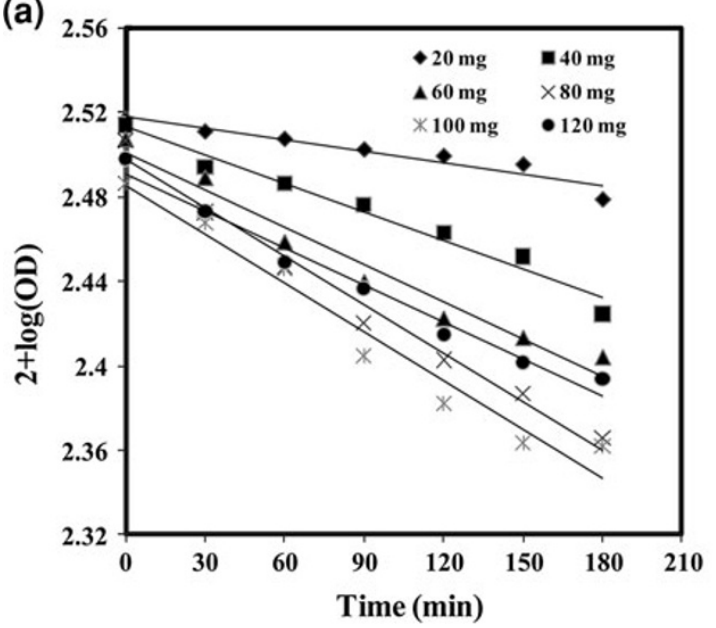

(c)

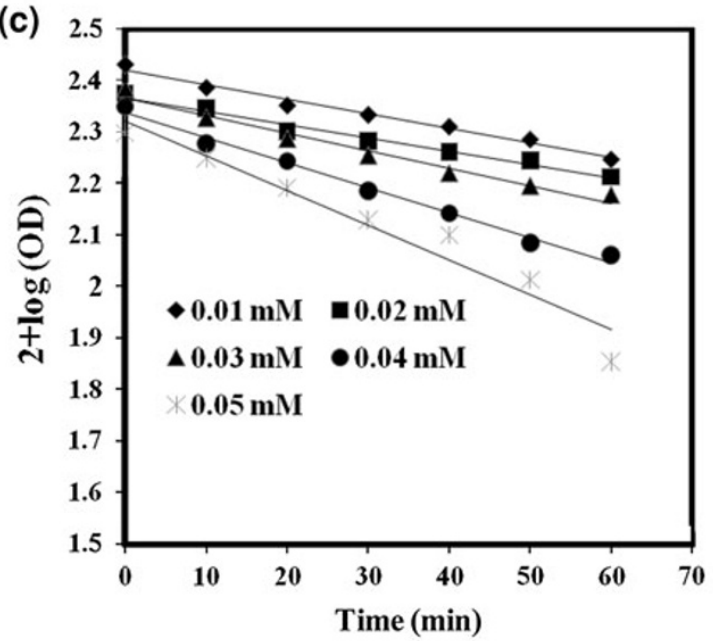

(e)

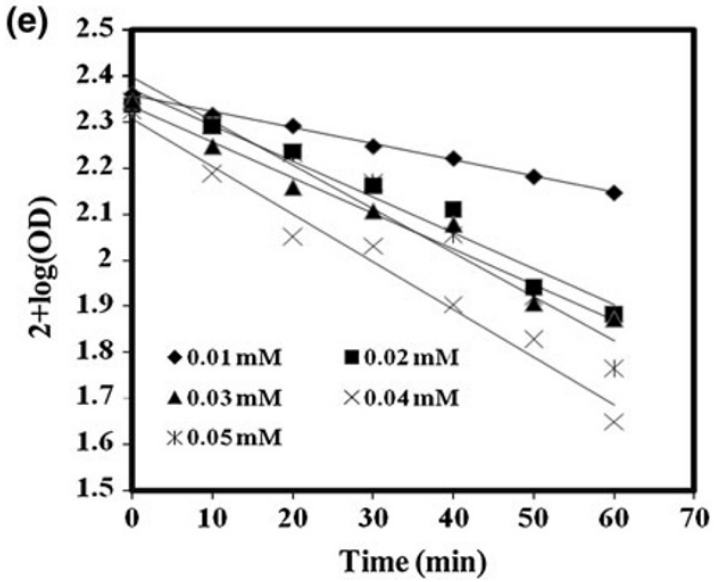

Fig. 4 a Plot of $2+\log (\mathrm{OD})$ versus reaction time in the presence of fixed initial concentration of $[\mathrm{MB}]=10^{-5} \mathrm{M}$ and $\mathbf{b}$ plot of decomposition rate for various amounts of Birnessite Nanorod $=20-120 \mathrm{mg} / \mathrm{L}$. c, d Plot of catalytic decomposition rate for various concentrations of PMS in the presence of fixed amount of birnessite nanorods $=100 \mathrm{mg} / \mathrm{L}$ and $[\mathrm{MB}]=10^{-5} \mathrm{M}$. e, f Plot of
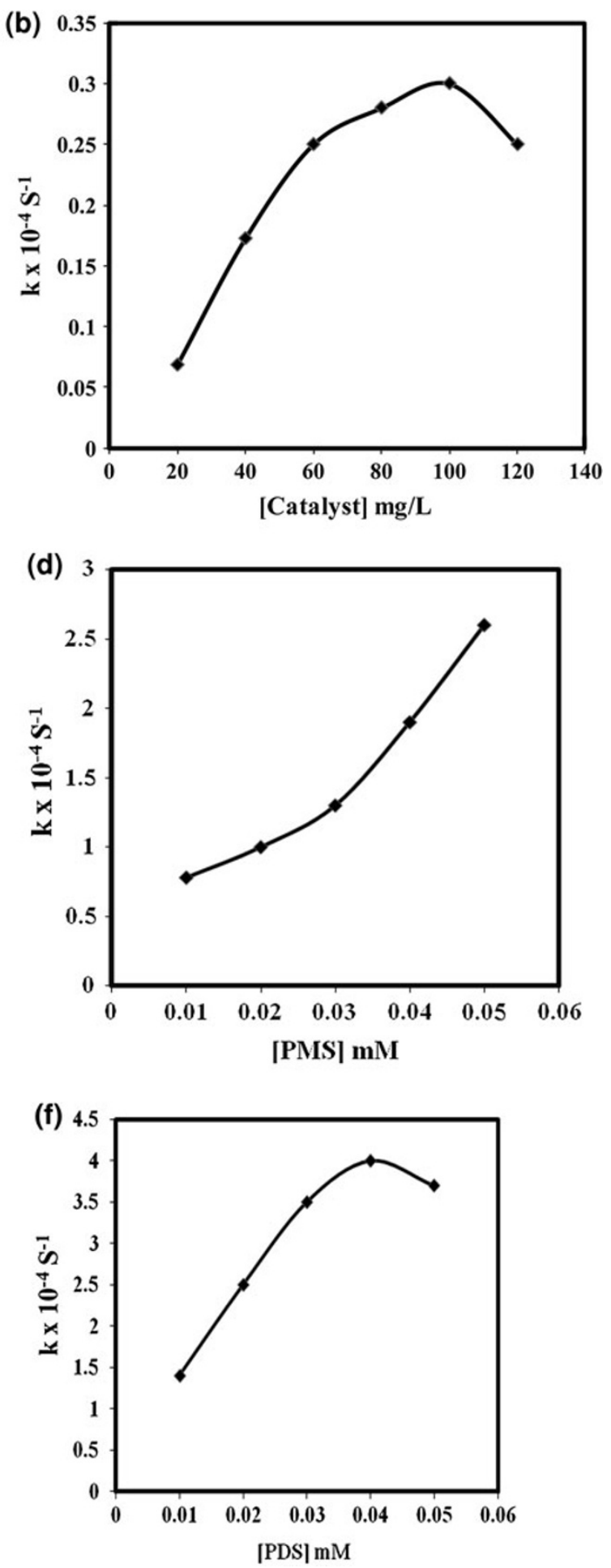

catalytic decomposition rate for various concentrations of PDS in the presence of fixed amount of birnessite nanorods $=100 \mathrm{mg} / \mathrm{L}$ and $[\mathrm{MB}]=10^{-5} \mathrm{M} . \mathbf{g}, \mathbf{h}$ Plot of catalytic decomposition rate for various concentrations of $\mathrm{H}_{2} \mathrm{O}_{2}$ in the presence of fixed amount of birnessite nanorods $=100 \mathrm{mg} / \mathrm{L}$ and $[\mathrm{MB}]=10^{-5} \mathrm{M}$ 

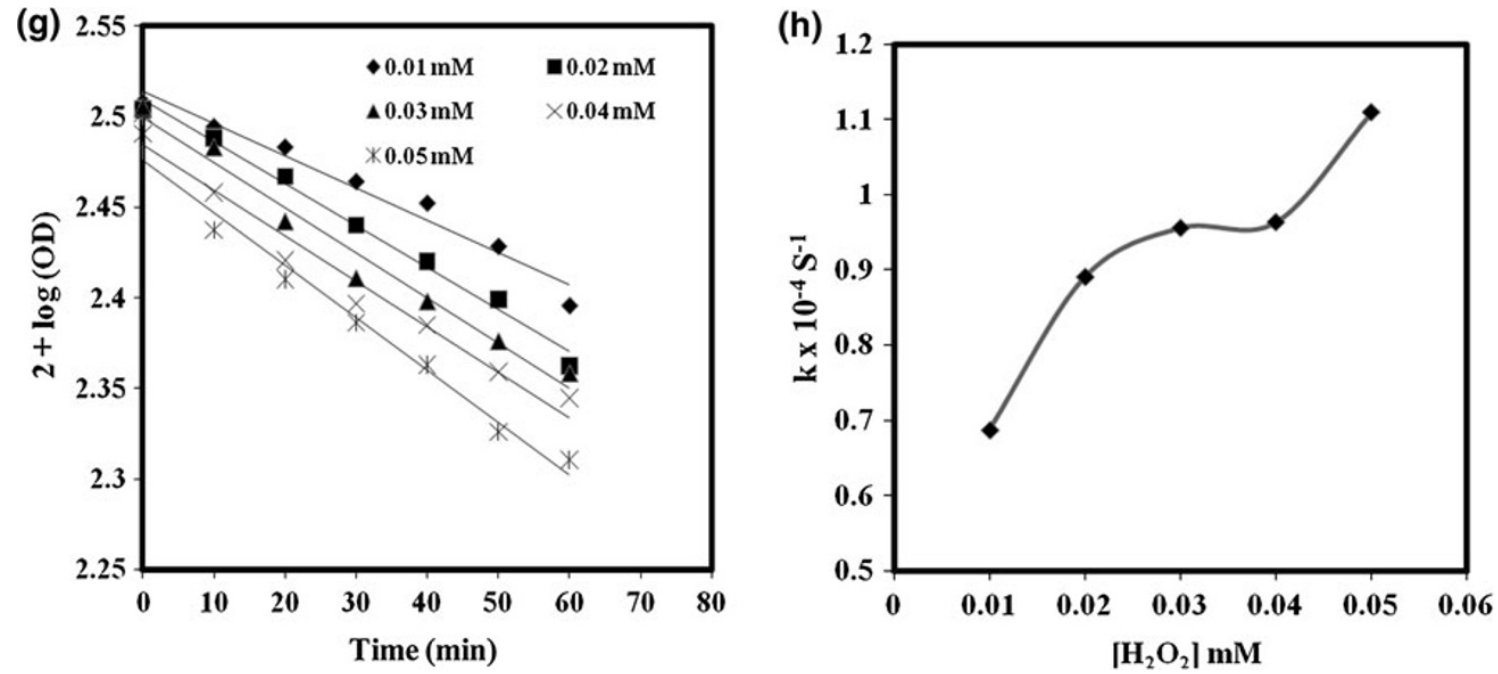

Fig. 4 continued

To evaluate the better oxidant for the BN-mediated catalytic decomposition of $\mathrm{MB}$, experiments were carried out under identical conditions, $[\mathrm{MB}]=250 \mathrm{ml}\left(10^{-5} \mathrm{M}\right)$, $[\mathrm{BN}]=100 \mathrm{mg} / \mathrm{L} \quad$ and $\quad[\mathrm{PMS}]=[\mathrm{PDS}]=\left[\mathrm{H}_{2} \mathrm{O}_{2}\right]=$ $0.04 \mathrm{mM}$ and the obtained results are shown in Fig. 5 . The results show that the PDS has higher degree of decomposition compared to the PMS. The redox potentials of PMS and PDS are about 1.82 and $1.70 \mathrm{eV}$, respectively. However, higher redox potential PMS has low reactivity than PDS, though both the oxidants produce $\mathrm{SO}_{4}^{-}$radical. This is due to the formation of caged radicals and it suppresses the availability of active sulphate radicals for decomposition of the dye molecules. At the room temperature, hydrogen peroxide demonstrates lower decomposition efficiency

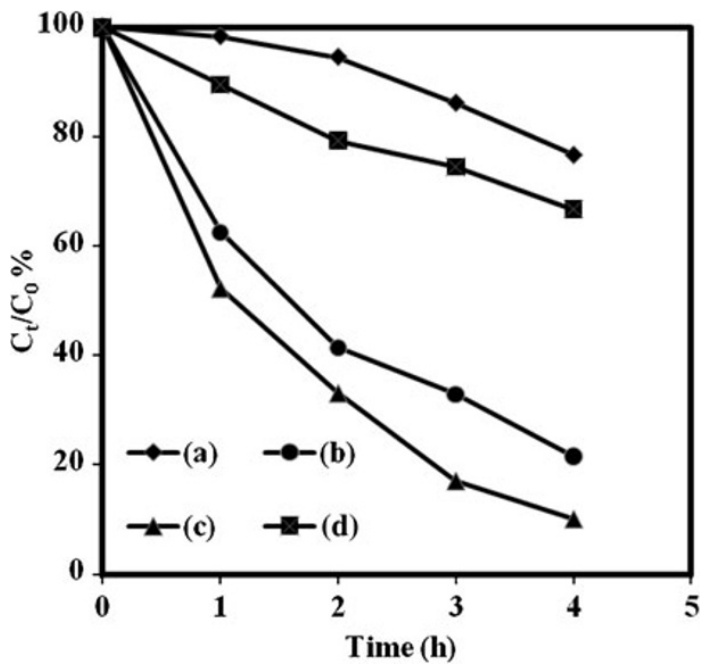

Fig. 5 Catalytic decomposition rate of methylene blue in the presence of birnessite nanorods $a$ without oxidants; with $b$ PMS, $c$ PDS and $d \mathrm{H}_{2} \mathrm{O}_{2}$ compared to PDS and PMS (Watts and Teel 2006). Among all these oxidants, PDS shows higher activity compared to other. In general, $\mathrm{H}_{2} \mathrm{O}_{2}$ with manganese oxide-mediated oxidant is an effective one, even though in most of the cases the hydroxyl radical generation would be possible only at a higher temperature. The hydroxyl radical produced readily recombine to produce water or some other by products. In such a condition, we cannot expect the pollutant to get degraded much. The sulfate radical produced by PMS is relatively of lower energy to degrade MB, compared to PDS at room temperature. The availability of sulfate radical is also more in PDS, which makes the catalyst a good one, to exhibit high stability and maintain same level of activity for ten cycles. Study of the reaction kinetics and the factors affecting the decomposition are underway.

\section{Conclusion}

The present study indicates the performance of catalytic decomposition of methylene blue in the presence of birnessite nanorods with common oxidants such as PDS, PMS and $\mathrm{H}_{2} \mathrm{O}_{2}$. Among these oxidants, PDS shows significantly improved catalytic activity in the presence of birnessite nanorods. This is due to the direct involvement of active sulphate radical and hydroxy radical. Furthermore, the reaction kinetics and application towards waste water treatment are underway.

Acknowledgments The authors thank the Management and the Authorities of Karunya University, Coimbatore, and The Sona College of Technology, Salem, for their kind support and encouragement.

Open Access This article is distributed under the terms of the Creative Commons Attribution License which permits any use, 
distribution, and reproduction in any medium, provided the original author(s) and the source are credited.

\section{References}

Andreozzy R, Caprio V, Insola A, Marotta R (1999) Catal Today $53: 51$

Anipsitakis GP, Dionysiou DD (2004) Environ Sci Technol 38:3705-3712

Brock SL, Duan N, Tian Z, Griraldo O, Zhou H, Suib SL (1988) Chem Mater 10:2619-2628

Furman O, Laine D, Blumenfeld A, Teel A, Shimizu K, Cheng IF, Watts RJ (2009) Environ Sci Technol 43:1528-1533
Furman OS, Teel AL, Watts RJ (2010) Environ Sci Technol 44:6423-6428

Kang L, Zhang M, Liu ZH, Ooi K (2007) Spectrochim Acta A 67:864-869

Kitajima N, Fukuzumi SI, Ono Y (1978) J Phys Chem 82:1505-1508

Parag RG, Aniruddha BP (2004) Adv Environ Res 8:501

Reisch MS (1988) Chem Eng News 66:7-14

Segal SR, Suib SL, Foland L (1997) Chem Mater 9:2526-2532

Suib SL (2008) J Mater Chem 18:1623-1631

Watts RJ, Teel AL (2006a) Toxic Radioact Waste Manage 10:2-9

Watts RJ, Teel AL (2006b) Pract Period Hazard Waste Manage 10:2-9

Zhang W, Yang Z, Wang X, Zhang Y, Wen X, Yang S (2006) Catal Commun 7:408

Zhou H, Shen YF, Wang JY, Chen X, O'Young CL, Suib SL (1998) J Catal 176:321-328 